\title{
AVALIAÇÃO DE PLANTAS MATRIZES DE ABACAXIZEIRO CULTIVAR SMOOTH CAYENNE UTILIZANDO MARCADORES RAPD E PADRÕES ISOENZIMÁTICOS
}

\author{
MARIA VITÓRIA CECCHETTI GOTTARDI ${ }^{2}$, ELIANA GERTRUDES MACEDO LEMOS ${ }^{3}$, \\ CARLOS RUGGIERO ${ }^{4}$
}

\begin{abstract}
RESUMO - Foram coletadas, em área comercial da fazenda Córrego dos Bois, município de Canápolis - MG, 20 plantas matrizes de abacaxizeiro cultivar Smooth Cayenne, para avaliação de similaridade e padrões genotípicos através de marcadores moleculares RAPD e padrões isoenzimáticos. As plantas matrizes foram selecionadas mediante as seguintes características: planta sadia, frutos cilíndricos, ausência de fasciação, pedúnculo curto, ausência de espinhos nas folhas, "olho" do fruto chato e peso dos frutos entre 1,6 a 2,2kg. Para análise de marcadores RAPD, foram testados 100 "primers", dos quais, 43 foram eficientes na amplificação das amostras, onde foram observados padrões de bandas diferentes entre as plantas matrizes utilizadas, indicando a existência de variabilidade genética. Nos padrões isoenzimáticos, dos 15 sistemas utilizados para revelação das amostras, 8 apresentaram atividade enzimática, sendo 5 deles com baixa resolução; entretanto, estes sistemas não foram eficientes em diferenciar as amostras devido à ausência de polimorfismo.
\end{abstract}

Termos para indexação: Ananas comosus, PCR, polimorfismo, variabilidade genética.

\section{EVALUATION OF MATRIX PLANTS OF PINEAPPLE SMOOTH CAYENNE CULTIVAR BY RAPD AND ISOZYMES ANALYSIS}

\begin{abstract}
Twenty matrix plants of pineapple cultivar Smooth Cayenne were collected from commercial area in the farm Córrego dos Bois, Canápolis city - MG, to evaluate similarity and genotypes patterns by both molecular markers, RAPD and isozymes analysis. Collected matrix plants presented the following characteristics: healthy plants, cylindrical fruits, no fasciation, short peduncle, spineless leaves, boring bubilles and fruit weight between 1,6 to $2,2 \mathrm{~kg}$. One hundred primers were tested to analyze RAPD patterns, within them, 43 were efficient to amplify the samples. Distinct patterns were observed among the matrix plants indicating that there is genetic variability. In relation to isozyme profiles, 15 isoenzyme systems were tested but only 8 revealed enzymatic activity, where 5 of them presented low resolution. In spite of this, the 8 systems weren't efficient to differentiate the samples not showing polymorphism.
\end{abstract}

Index terms: Ananas comosus, PCR, polymorphism, genetic variability.

\section{INTRODUÇÃO}

O Brasil situa-se como um dos maiores produtores mundiais de abacaxi, tendo sido estimada em 1,7 milhão de toneladas a produção brasileira em 1999 ( FAO 2000).

Entre as cultivares de abacaxi mais cultivadas no Brasil, destacam-se Smooth Cayenne (Cayenne) e Pérola (Pernambuco), sendo utilizadas para o mercado de fruta fresca e pequena quantidade para exportação. Atualmente, a preferência dos importadores, sobretudo da Europa e Estados Unidos, tem sido pela cultivar Smooth Cayenne (Gorgatti et al., 1996).

Apesar da grande demanda no mercado mundial de frutas, o abacaxi ainda não conseguiu destacar-se no cenário agrícola brasileiro, apresentando baixo consumo " per capita" e pequena contribuição para a renda agrícola (Cunha et al., 1994).

A falta de seleção de plantas matrizes para obtenção de mudas tem sido um fator limitante para a cultura do abacaxi. Devido ao fato de ser uma planta propagada vegetativamente, muitas lavouras são iniciadas sem nenhum critério de seleção, inclusive com mudas contaminadas, o que tem contribuído para a disseminação de pragas e doenças (Ruggiero et al., 1994).

A qualidade do material de plantio é fator decisivo para obtenção de lavouras uniformes, de bom estado fitossanitário e altamente produtivas, onde a seleção de plantas matrizes é de suma importância para o sucesso econômico da cultura, resultando na melhoria genética com reflexos positivos sobre a produção de abacaxi.

A seleção de plantas matrizes consiste em realizar, antes da colheita dos frutos, uma inspeção no abacaxizal, marcando-se as plantas que apresentam o maior número de caracteres desejáveis, para posterior multiplicação (Reinhardt, 1982). O procedimento de seleção de plantas é importante devido à taxa de mutação que ocorre na lavoura, em torno de $6 \%$, onde os indivíduos indesejáveis são eliminados, além de contribuir para uma drástica redução da fusariose, doença de maior importância econômica para a cultura no Brasil (Ruggiero et al., 1999).

\footnotetext{
1 (Trabalho 255/2000). Recebido: 21/11/2000. Aceito para publicação: 16/10/2001. Parte da dissertação de doutorado da primeira autora. Projeto financiado pela FAPESP

2 Pós Doutoranda do Departamento de Tecnologia, FCAV-Unesp - vitoria@fcav.unesp.br

3 Profa Titular do Departamento de Tecnologia,FCAV-Unesp - egerle@fcav.unesp.br

4 Prof. Titular de Fruticultura, do Departamento de Produção Vegetal, FCAV-Unesp - ruggiero@fcav.unesp.br
} 
Através de observações de campo, verifica-se que existe uma considerável variabilidade genética no material Smooth Cayenne atualmente cultivado no Brasil, o que pode ser comprovado por uma simples caminhada em uma lavoura comercial de abacaxi, onde são encontradas plantas com pedúnculo curto e longo, folhas com e sem espinhos, fasciação, entre outros ( Ruggiero et al., 1999). Este fato está em acordo com as observações realizadas por Collins (1960), que considera a cultivar Smooth Cayenne como uma coleção de clones. No entanto, para alguns pesquisadores brasileiros, a Smooth Cayenne é um material homogêneo.

Muitos estudos realizados têm enfatizado aspectos à seleção individual de características desejáveis em programas de melhoramento (Usberti Filho et al., 1995). Técnicas isoenzimáticas como marcadores genéticos estão sendo utilizadas com sucesso em plantas de abacaxi visando, principalmente, à identificação de cultivares (Dewald et al., 1988) e estudos genéticos e taxonômicos (Dewald et al.,1992; Aradhya et al., 1994), entre outros.

Outra forma de caracterização dos recursos biológicos pode ser realizada através da amplificação de fragmentos de DNA amplificados ao acaso (RAPD). Esta técnica, realizada através de PCR (reação em cadeia da polimerase), utiliza "primers" decanucleotídios de seqüência arbitrária, o que tende a produzir uma freqüência relativamente alta de polimorfismo por "primer", sendo o método rápido e eficiente (Fairbanks et al., 1993). Os “ primers" de seqüência aleatória têm sido utilizados para reproduzir segmentos de DNA genômico em várias espécies de plantas (Willians et al., 1993), sendo útil no auxílio à pesquisa de caracterização de recursos biológicos (Fairbanks et al.,1993).

Em abacaxi, as relações genéticas entre diferentes cultivares foram determinadas através do RAPD por Ruas et al.(1995), os quais sugerem que esta análise possa ser usada de maneira eficiente para caracterização de recursos genéticos no gênero Ananas. E no caso da cultivar Smooth Cayenne, embora seja constatada no campo uma variabilidade morfológica nas plantas, não existem estudos, até o momento, sobre a variabilidade genética dentro desta cultivar. Em vista disto, o presente estudo teve como objetivo avaliar padrões genotípicos e similaridade dentro da cultivar Smooth Cayenne, empregando-se marcadores bioquímicos e moleculares.

\section{MATERIAL E MÉTODOS}

\section{Análise por marcadores RAPD}

Foram coletadas amostras de folhas de 20 plantas adultas de abacaxizeiro cultivar Smooth Cayenne, em área comercial existente na Fazenda Córrego dos Bois, município de Canápolis - MG. Para esta coleta, selecionaram-se plantas com as seguintes características: ausência de espinhos nas folhas (excetuando-se alguns espinhos rudimentares no ápice, típico da cultivar Smooth Cayenne); "olho" dos frutos de aspecto achatado; ausência de fasciação; pedúnculo curto e frutos cilíndricos com peso de aproximadamente 1,6 a $2,2 \mathrm{~kg}$.

Para a extração do DNA, foi utilizado o tecido da parte basal das folhas de plantas de abacaxizeiro, baseada no método proposto por Saghai-Maroof et al. (1984). A quantificação do DNA foi realizada em espectrofotômetro, medindo-se a absorbância no comprimento de onda de 260 e 280nm. A reação de amplificação constituiu-se de 30 ng de DNA genômico, tampão de PCR (GIBCO-BRL) $1 \mathrm{X}, \mathrm{MgCl}_{2} 1,5 \mathrm{mM}$ (GIBCO-BRL), $200 \mathrm{mM}$ de dNTPs, 1,0u de Taq DNA polimerase (GIBCO-BRL), $0,22 \mathrm{mM}$ de "primer", água milli Q filtrada q.s.p. 20mL. Os tubos foram colocados em um aparelho termociclador (PTC-100 Programable Thermal Controler- MJ Reserch, Inc.) e submetidos a um ciclo de: $92^{\circ} \mathrm{C}$ por 3 minutos, 47 ciclos à $92^{\circ} \mathrm{C}$ por 1 minuto, $36^{\circ} \mathrm{C}$ por 1 minuto e 45 segundos e $72^{\circ} \mathrm{C}$ por 2 minutos e, finalmente, um ciclo $72^{\circ} \mathrm{C}$ durante 7 minutos (Ruas et al., 1995). O conjunto de "primers" utilizados foram os produzidos pela Operon Tecnologies, Inc. (Operon B-K) e os da University of British Columbia (RAPD Oligo Project) - Biotechnology Laboratory. As amostras amplificadas foram submetidas à eletroforese (100V1h30min) em gel de agarose a 1,5\%, dissolvido em tampão TEB [89 mM - ácido bórico, 89mM - Tris, 2,5mM - EDTA, contendo brometo de etídio $(5 \mu \mathrm{g} / \mathrm{mL})$ e $\mathrm{H}_{2} \mathrm{O}$ milli- Q]. Como padrão de peso molecular, foi utilizado "ladder" de $1 \mathrm{~kb}$ (GIBCO-BRL). A visualização dos resultados foi realizada em equipamento de fotodocumentação (Gel Doc- 1000 - BioRad).

Com os dados obtidos, elaborou-se uma matriz binária, a qual foi analisada pelo método de agrupamento hierárquico UPGMA - "Unweighted Pair Group Method with Arithmetic Mean", através do programa SHAN do NTSYS ("Numeral Taxonomy and Multivariate Analysis System"- Rohlf \& Slice, 1992). Empregou-se a análise do bandeamento produzido por cada "primer", sendo conferido o parâmetro ausência ou presença de bandas, onde 1 indica a presença de banda e zero a ausência de banda (0/1). Para o cálculo da matriz de similaridade, foi utilizado o coeficiente de Jaccard.

\section{Determinação de Padrões Isoenzimáticos}

Para a extração das isoenzimas foi utilizado $1,0 \mathrm{~g}$ de tecido da parte basal das folhas de abacaxi de cada amostra, macerado com $1 \mathrm{~mL}$ de água milli-Q. Em seguida, o macerado foi filtrado em gaze e o material recolhido foi centrifugado a $5^{\circ} \mathrm{C}$ por 5 minutos a 17.949 x g para a retirada das impurezas. Para cada $1 \mathrm{~mL}$ de sobrenadante coletado, foi adicionado $2 \mathrm{~mL}$ de glicerol $20 \%$.

A eletroforese foi realizada em gel de poliacrilamida $10 \%$, utilizando-se do sistema contínuo de tampão. Nesta técnica, foi utilizado o sistema mini Protean (BioRad), aplicando-se um volume de $40 \mathrm{~mL}$ do sobrenadante acrescido de glicerol $20 \%$ por canaleta. A solução-tampão utilizada nos eletrodos foi $0,0125 \mathrm{M}$ TRIS e $0,096 \mathrm{M}$ Glicina, $\mathrm{pH} 8,8$. A eletroforese foi conduzida a $4^{\circ} \mathrm{C}$ por 7 horas a $50 \mathrm{~V}$ e os géis foram preparados e revelados.

Foram analisados 15 sistemas isoenzimáticos, sendo eles: Álcool Desidrogenase (ADH); Superóxido Dismutase (SOD); aEsterase (EST); b-Esterase (EST); Fructokinase (EK); Glicose 6fosfato Desidrogenase (G6PD); NAD Glicose Desidrogenase (GDH); Aldeído Oxidase (AO); Sorbitol Desidrogenase (SDH); Glutamato Desidrogenase (GLD); 3-Hidroxibutirato Desidrogenase (HBDH ); Octanol Desidrogenase (ODH), revelados segundo metodologia proposta por Pasteur et al., (1988); Peroxidase (PO) e Fosfoglicose Isomerase (PGI), segundo metodologia proposta por Alfenas (1998); Arabinose Desidrogenase (ARADH), segundo Lemos (1994).

Estimou-se o coeficiente de mobilidade (Rf) das bandas de interesse, sendo utilizada a seguinte fórmula:

$\mathrm{Rf}=$ distância percorrida pela isoenzima distância percorrida pelo corante 


\section{RESULTADOS E DISCUSSÃO}

\section{Marcadores RAPD}

O emprego da técnica RAPD demonstrou a existência de diferença genética no material em estudo. Dentre os 100 "primers" utilizados, 43 proporcionaram eficiência na amplificação das amostras (Tabela 1), onde se obteve um total de 777 bandas polimórficas e 9 bandas monomórficas. Constatou-se que 57 "primers" não amplificaram nenhuma das amostras, indicando que estas não apresentam uma região de homologia com tais "primers".

Os "primers" selecionados geraram um número apreciável de bandas, onde apenas as bandas intensas foram analisadas. Segundo Ferreira \& Grattapaglia (1996), a maior ou menor intensidade com que uma banda RAPD é visualizada, é um reflexo direto do grau de competitividade do sítio no genoma, ou seja, quanto mais competitivo o sítio, mais interpretável, reproduzível e robusto será aquele marcador em ensaios sucessivos.

De um modo geral, podem-se observar padrões de bandas diferentes, indicando a existência de variabilidade genética entre as matrizes utilizadas. Apesar de estas plantas matrizes serem da mesma cultivar e apresentarem as mesmas características fenotípicas, esta variabilidade genética pode estar relacionada com o processo de propagação do abacaxizeiro, o qual é realizado vegetativamente, onde as lavouras são formadas por mudas provenientes de várias plantas, constituindo, desta forma, uma mistura de clones. Collins (1960) salienta que a cultivar Smooth Cayenne é formada por uma coleção de clones, e Lacoeuilhe (1982) considera esta cultivar uma família de clones em mistura. Essa variabilidade genética pode ser visualizada através da Figura 1 , onde se observa um grande número de bandas polimórficas. Entretanto, encontrou-se também bandas monomórficas (Figura 2), as quais estão relacionadas com as características da variedade em estudo.

Ao analisar o dendrograma (Figura 3), verificou-se que as plantas estudadas encontram-se reunidas em 2 grupos: A e B. No grupo B, encontram-se as plantas matrizes 3 e 16, apresentando um grau de semelhança entre ambas de aproximadamente $10 \%$, sendo estas consideradas diferentes das demais plantas. No grupo A, encontram-se o restante das plantas matrizes, divididas em vários subgrupos, as quais apresentam diferentes graus de similaridade entre si, variando de $12,4 \%$ a $26,8 \%$. De um modo geral, pode-se observar que o grau de similaridade entre as plantas é baixo, levando-se em consideração que estas são da mesma variedade, confirmando-se a existência de variabilidade genética no material Smooth Cayenne.

\section{Determinação de Padrões Isoenzimáticos}

Dentre os 15 sistemas isoenzimáticos analisados, a Glicose 6 fosfato Desidrogenase (G6PD), Superoxide Dismutase (SOD) e a Glutamato Desidrogenase (GDH) apresentaram atividade enzimática; Álcool Desidrogenase (ADH), Peroxidase (PO), Fosfoglicose Isomerase (PGI) e a 3-Hidroxibutirato Desidrogenase (HBDH) apresentaram baixa atividade; a e b Esterase (EST), Aldeído Oxidase (AO), Sorbitol Desidrogenase (SDH ), Octanol Desidrogenase (ODH ), Arabinose Desidrogenase (ARADH) e a NAD Glicose Desidrogenase (GDH), não sendo observada atividade para estas enzimas.

Resultados semelhantes em relação à atividade enzimática
TABELA 1 - Relação dos "primers" utilizados para análise de RAPD, com suas respectivas seqüências.

\begin{tabular}{|c|c|}
\hline " & $\begin{array}{c}\text { SEQ ÜÊENCIA } \\
\left(5^{\prime}-3^{\prime}\right)\end{array}$ \\
\hline \multicolumn{2}{|c|}{ Operon-KIT C } \\
\hline $\begin{array}{l}\text { OPC }-04 \\
\text { OPC }-06 \\
\text { OPC-09 } \\
\text { OPC-12 } \\
\text { OPC }-15 \\
\text { OPC }-18\end{array}$ & $\begin{array}{l}\text { CCGCATCTAC } \\
\text { GAACGGACTC } \\
\text { CTCACCGTCC } \\
\text { TGTCATCCCC } \\
\text { GACGGATCAG } \\
\text { TGAGTGGGTG }\end{array}$ \\
\hline \multicolumn{2}{|c|}{ University of British Columbia. } \\
\hline 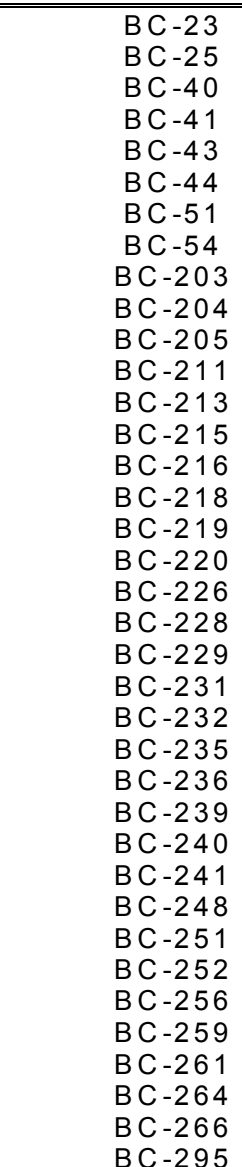 & $\begin{array}{l}\text { CCCGCCTTCC } \\
\text { ACAGGGCTCA } \\
\text { TTACCTGGGC } \\
\text { TTACCGGGG } \\
\text { AAAACCGGGC } \\
\text { TTACCCCGGC } \\
\text { CTACCCGTGC } \\
\text { GTCCCAGAGC } \\
\text { CACGGCGAGT } \\
\text { TTCGGGCCGT } \\
\text { CGGTTGGAA } \\
\text { GAAGCGCGAT } \\
\text { CAGCGAACTA } \\
\text { TCACACGTGC } \\
\text { CATAGACTCC } \\
\text { CTCAGCCCAG } \\
\text { GTGACCTCAG } \\
\text { GTCGATGTCG } \\
\text { GGGCCTCTAT } \\
\text { GCTGGGCCGA } \\
\text { CCACCCAGAG } \\
\text { AGGGAGTTCC } \\
\text { CGGTGACATC } \\
\text { CTGAGGCAAA } \\
\text { ATCGTACGTG } \\
\text { CTGAAGCGGA } \\
\text { ATGTCCAGG } \\
\text { GCCCGACGCG } \\
\text { GAGTCTACCG } \\
\text { CTTGACGGGG } \\
\text { CTGGTGATGT } \\
\text { TGCAGTCGAA } \\
\text { TGCAGTCGAA } \\
\text { CTGGCGTAC } \\
\text { TCCACCGCGC } \\
\text { CCACTCACCG } \\
\text { GGGCGCCTAG }\end{array}$ \\
\hline
\end{tabular}

TABELA 2 - Relação do Rf das bandas das isoenzimas que apresentaram atividade enzimática nas amostras utilizadas.

\begin{tabular}{l|c}
\hline \hline \multicolumn{1}{c|}{ ISOENZIMAS } & Rf \\
\hline \hline Glicose-6-Fosfato-Desidrogenase (G6PD) & 0,11 \\
\hline \multirow{2}{*}{ Superoxide Dismutase (SOD) } & 0,11 \\
& 0,18 \\
\hline Glutamato Desidrogenase (GDH) & 0,33 \\
\hline Álcool Desidrogenase (ADH) & 0,05 \\
\hline & 0,14 \\
& 0,41 \\
Peroxidase (PO) & 0,44 \\
& $0,58^{*}$ \\
\hline Fosfoglicose Isomerase (PGI) & $0,64^{*}$ \\
\hline 3-Hidroxibutirato Desidrogenase (HBDH) & $0,66^{*}$ \\
\hline \hline
\end{tabular}

* Bandas presentes apenas na amostra de número 4. 




FIGURA 1 - Padrões de bandeamento de fragmentos de DNA amplificados por RAPD, utilizando-se do "primer" British Columbia 218: $(\mathrm{CN})$ controle negativo, $(\mathrm{P})$ padrão de peso molecular $1 \mathrm{~Kb}$, (1 a 20) amostras de plantas matrizes (setas) indicam bandas polimórficas.

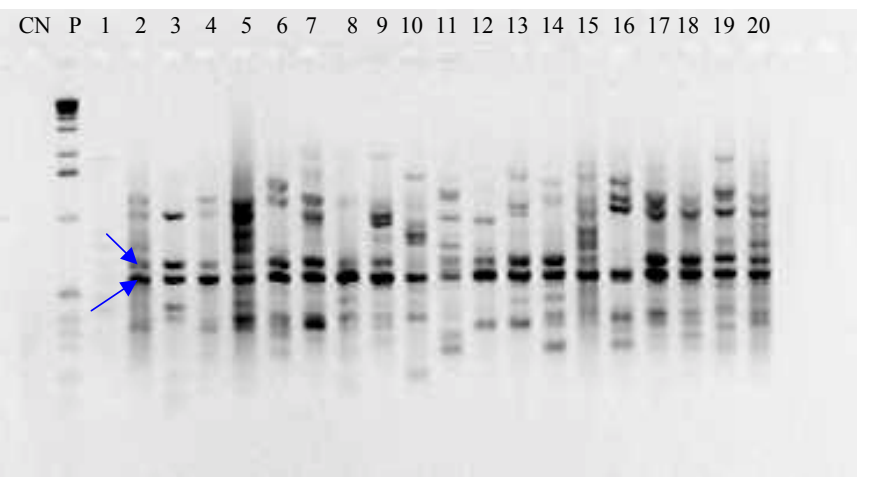

FIGURA 2 - Padrões de bandeamento de fragmentos de DNA amplificados por RAPD, utilizando-se do "primer" British Columbia 231: (CN) controle negativo, $(\mathrm{P})$ padrão de peso molecular $1 \mathrm{~Kb},(1 \mathrm{a} 20)$ amostras de plantas matrizes (setas) indicam bandas monomórficas.

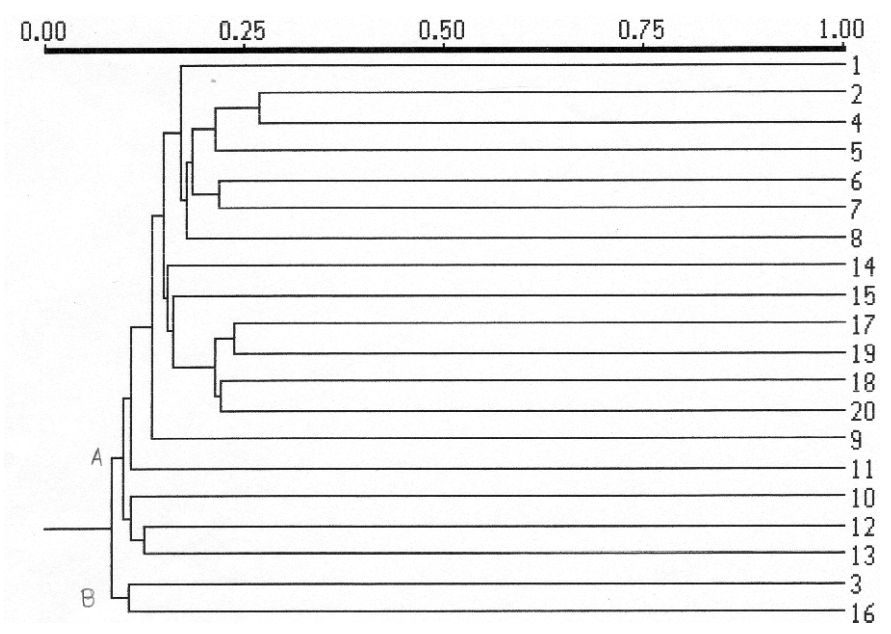

FIGURA 3 - Dendrograma construído pelo método UPGMA que relaciona as plantas matrizes de abacaxizeiro cultivar Smooth Cayenne (1 a 20) amostras das plantas matrizes.

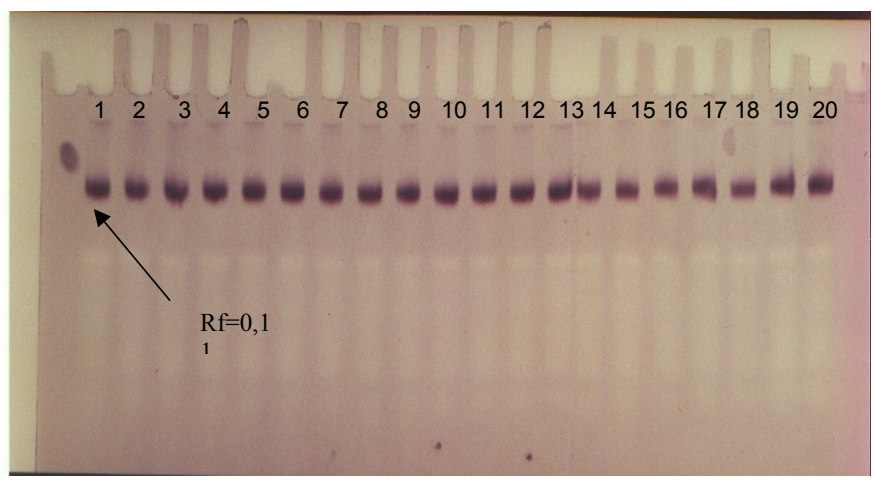

FIGURA 4 - Perfil eletroforético do sistema enzimático Glicose-6Fosfato Desidrogenase (G6PD) das amostras de plantas matrizes. Canaletas: 1 a 20 plantas matrizes.

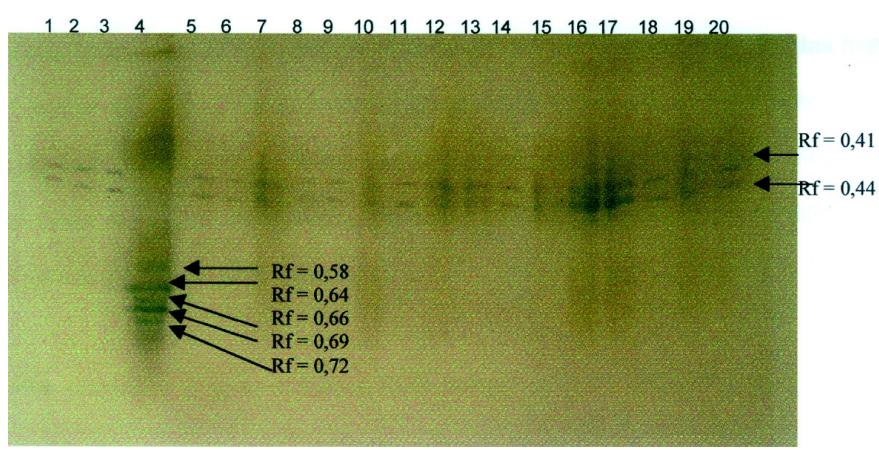

FIGURA 5 - Perfil eletroforético do sistema enzimático Peroxidase (PO) das amostras das plantas matrizes. Canaletas: 1 a 20 plantas matrizes

foram encontrados por De Wald et al. (1992) nos sistemas izoenzimáticos Superoxide Dismutase (SOD), a e b Esterase (EST) e por Ballve et al. (1995) em relação à Glicose 6 fosfato Desidrogenase (G6PD), a e b esterase (EST). Entretanto, Ballve et al. (1995) não obtiveram atividade enzimática no sistema Glutamato Desidrogenase, enquanto Dewald et al. (1992) e Aradya et al. (1994) obtiveram uma baixa atividade com a Glicose 6 fosfato Desidrogenase, diferindo dos resultados obtidos. Este fato pode estar relacionado com a idade da planta utilizada nas amostras para extração das isoenzimas, uma vez que, em estádios diferentes de desenvolvimento da planta, podem ocorrer diferenças na atividade enzimática (Ferreira \& Grattapaglia, 1996), onde folhas novas, completamente expandidas, de mudas tendem a fornecer extratos de maior atividade enzimática que as folhas novas, de plantas adultas (Alfenas,1998). Entretanto, neste trabalho, foram utilizadas para extração das isoenzimas folhas de plantas adultas, em fase de colheita dos frutos.

Em todos os sistemas isoenzimáticos que apresentaram atividade, não foi possível verificar diferença entre as 20 matrizes utilizadas, pois estas não apresentaram polimorfismo (Tabela 2). Como exemplo, pode-se observar, na Figura 4, o perfil isoenzimático da Glicose-6-Fosfato-Desidrogenase, apresentando uma banda monomórfica para todas as amostras com Rf $=0,11$.

Apenas no sistema Peroxidase (PO) a amostra de número 4 das plantas matrizes, além da ocorrência de bandas monomórficas $(\mathrm{Rf}=0,41 \mathrm{e} \mathrm{Rf}=0,44)$, apresentou outras diferentes com $\mathrm{Rf}=0,58 ; 0,64 ; 0,66 ; 0,69$ e 0,72 , respectivamente (Figura 5). Embora as condições ambientais, bem como a metodologia 
utilizada para análise de padrões isoenzimáticos, tenham sido os mesmos para todas as amostras, algum fator intrínseco desta planta levou à ocorrência de um bandeamento diferente. Tal fato pode estar relacionado a um ataque de praga ou doença, pois segundo Cordeiro \& Sá (2000), o peróxido de hidrogênio é formado nas etapas iniciais da resposta de defesa da planta.

\section{CONCLUSÕES}

1. A cultivar Smooth Cayenne pode ser considerada como uma coleção de clones em mistura.

2. Através dos marcadores RAPD, comprovou-se a existência de elevada variabilidade genética no material Smooth Cayenne cultivado no Brasil.

3. Em todos os sistemas isoenzimáticos utilizados, as amostras não diferiram entre si, apresentando monomorfismo em todas as amostras de plantas matrizes.

\section{AGRADECIMENTOS}

À FAPESP pelo suporte financeiro, processo n ${ }^{\circ}$ 99/06526-0.

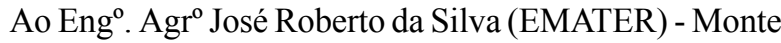
Alegre de Minas - MG, pelo auxílio na coleta das plantas matrizes em Canápolis - MG.

\section{REFERÊNCIAS BIBLIOGRÁFICAS}

ALFENAS, A C. Eletroforese de isoenzimas e proteínas afins: fundamentos e aplicações em plantas e microrganismos. Viçosa: UFV,1998.574p.

ARADHYA, M.K., ZEE, F., MANSHARDT, R.M. Isoenzyme variation in cultivated and wild pineaple. Euphytica, Dordrecht, v.79, p.87-99, 1994.

BALLVE, R.M.L. et al. Methodology for starch gel electrophoresis and protocols for isozymes of 32 plant genera. Revista Brasileira de Genética, Campinas, v.18, n.3, p.491-502, 1995.

COLLINS, J.L. The pineaple, London: Leonard-Hill, 1960. 293p.

CORDEIRO, M.C.R.; SÁ, M.F.G. Biotecnologia e resistência a patógenos. Disponível em: http:/www.biotecnologia.com.br. Acesso em: 20 de jan. de 2000.

CUNHA, G.A P. et al. Abacaxi para exportação: aspectos técnicos da produção. Brasília: Frupex, 1994. 41p.

DEWALD, M.G.; MOORE, G.A.; SHERMAN, W.B. Identification of pineapple cultivars by isozyme. Journal of American Society of Horticultural Science, Alexandria, v.113, n.6, p. 935-938, 1988.

DEWALD, M.G.; MOORE, G.A.; SHERMAN, W.B. Izoenzimes in Ananas (pineapple): genetics and usefulness in taxonomy. Journal of American Society of Horticultural Science, Alexandria, v.117,n. 3, p.491-496, 1992.
FAIRBANKS, D.J. et al. Efficient characterization of biological diversity using field DNA extraction and random amplified polymorphic DNA markers. Revista Brasileira de Genética, Campinas, v.16, n.1, p.11-22, 1993.

FAO. Site FAO (2000).http://apps.fao.org/, consulta realizada em 5 de abril de 2000.

FERREIRA, M.E.; GRATTAPAGLIA, D. Introdução ao uso de marcadores moleculares em análise genética. Brasília: Embrapa, 1996.220p.

GORGATTI, A N. et al. Abacaxi para exportação: procedimentos de colheita e pós-colheita. Brasília: Frupex, 1996. 41p.

LACOEUILHE, J.J. As cultivares comerciais de abacaxi. In: SIMPÓSIOBRASILEIRO SOBRE ABACAXICULTURA, 1., 1982, Jaboticabal. Anais...Jaboticabal: FCAV, 1982. p.61-75.

LEMOS, E.G.M. Classificação e identificação de bradirrizóbios que nodulam soja por análise de padrões isoenzimáticos, sorologia, morfologia de colônias e atividade de hidrogenase. 1994. 108f. Tese (Livre-Docência) - Faculdade de Ciências Agrárias e Veterinárias, Universidade Estadual Paulista, Jaboticabal, 1994.

PASTEUR, N. et al. Pratical isozyme genetics. Chinchester: Ellis Horwood, 1988. 209p.

REINHARDT, D.H.R.C. Propagação do abacaxizeiro: método usual e por secções do caule. In: SIMPÓSIO BRASILEIRO SOBRE ABACAXICULTURA, 1., 1982, Jaboticabal. Anais... Jaboticabal: FCAV, 1982.p.47-59.

ROHLF, F.J., SLICE, D.E. NTSYS - Numerical taxonomy and multivariate analysis system. New York: Exater Software, 1992. $115 \mathrm{p}$.

RUGGIERO, C. et al. Controle integrado da fusariose do abacaxizeiro. Jaboticabal: FUNEP, 1994. 81p.

RUAS, P.M. et al. Genetic relationship among four varieties by pineaple, Ananas comosus, reveable by random amplified polymorphic DNA (RAPD) analysis. Revista Brasileira de Genética, Campinas, v.18, n.3, p. 413-416, 1995.

SAGHAI-MAROOF, et.al., Ribossomal DNA spacerlength polymorphisms in barley: mendelian inheritance, chromossomal location, and population dynamics. PNAS, London, v.81, p. 8014$8018,1984$.

USBERTI FILHO, J.A. et al. Inheritance of leaf spininess and segregation of leaf color in pineaple (Ananas comosus L.Merrill) Revista Brasileira de Genética, Campinas, v.18, n. 4, p. 547-552, 1995.

WILLIANS, J.G.K. et al. DNA polymorphism amplified by arbitrary primers are useful as genetic markers. Nucleic Acids Research, Oxford. v.18, p.6531-6535,1993. 